the plunger and the plunger tube tightly, else the plunger will not remain in the proper place. The coarse adjustment with such an arrangement is best made by moving the plunger through the stopper, and the fine adjustment by turning both the stopper and plunger, applying at the same time a gentle pull or push. This simple modification of the apparatus is given since the brass attachments are not always readily obtained and are troublesome to make.

The use of a fixed platinum wire has its advantages. Great care need not be taken in the centering of the platinum wire, for if after the wire has been soldered to the cap it is found to be off center, simple bending, as shown in the figure, will remedy this. In the ordinary regulator the electrical connection between the movable platinum wire and the binding post is made through a screw and nut. When the threads become worn or corroded this connection often becomes uncertain and may give rise to considerable trouble. With a fixed wire it is possible to solder the wire, cap and binding post together, thus eliminating any such source of trouble.

JohN B. Ferguson.

\author{
GEOPHYGICAL LABORATORY, \\ Carnetgin Institution of Waghinoton, \\ WAsHingtoN, D. C.
}

\title{
ON SOME HALOGEN DERIVATIVES OF AROMATIC AMINES \\ AND THEIR ANALYSIS. I. ${ }^{1}$
}

By F. B. Dains, T. H. Vaugran and W. M. Janney.

Received January 9, 1918.

In the course of the study of the effect of the halogens on the reactivity of the aromatic amines, it became necessary to prepare certain iodine substitution products of these amines, and the following paper contains some results of this phase of the work. Hofman ${ }^{2}$ showed that aniline reacted directly with iodine yielding $p$-iodoaniline. Later Wheeler ${ }^{3}$ and his students investigated the action of iodine on the toluidines and found that substitution products were easily obtained. Our experiments indicate that the chloro- or bromo-substituted anilines are capable of reacting in an analogous fashion with the formation of chloroiodo and bromoiodo derivatives.

The Introduction of Iodine into the Bromoanilines.

Preparation of 4-Bromo-2-iodoaniline.-The general procedure of Wheeler was followed with satisfactory results. A mixture of $25 \mathrm{~g}$. of 4-bromoaniline and $37 \mathrm{~g}$. of iodine was heated under a reflux condenser with $18 \mathrm{~g}$. of pure calcium carbonate, $60 \mathrm{cc}$. of ether and $60 \mathrm{cc}$. of water.

${ }^{1}$ Owing to the departure of two of the authors, the investigation, though incomplete, is published. The work will be continued in this laboratory.

"Ann. chim. 67, 61 (1848).

${ }^{3}$ Am. Chem. J., 42, 441, 448 (1909); 44, 127, 500 (1910). 
After several hours the iodine disappeared and a black oily product which solidified on cooling settled to the bottom of the flask. The black solid is soluble in ether, alcohol, benzene and gasoline. It is best purified by solution in dilute alcohol, from which it can be obtained, after repeated crystallization, in fine white needles, melting at $71^{\circ}$.

Calc. for $\mathrm{C}_{6} \mathrm{H}_{5} \mathrm{NBrI}: \mathrm{N}, 4.7 \mathrm{I}$. Found: $4.76,4.69$.

That the iodine atom is in the 2-position is proved indirectly by the fact that this substance is different from the only other possible isomer, namely the 4-bromo-3-iodoaniline, which had been previously obtained by Wheeler and Valentine. ${ }^{1}$ Other evidence is the following: The above aniline was diazotized and the amine group removed. The resulting bromo-iodobenzene gave on nitration yellow crystals melting at $85^{\circ}$, corresponding to the 4-bromo-2-iodo-I-nitrobenzene.

Derivatives of 4-Bromo-2-iodoaniline.-The hydrochloride prepared from the aniline dissolved in benzene, and dry hydrogen chloride, melts at $205^{-} 6^{\circ}$.

Calc. for $\mathrm{C}_{6} \mathrm{H}_{6} \mathrm{NBrI} . \mathrm{HCl}: \mathrm{HCl}$, 10.70. Found: 10.90.

Acetic anhydride readily gives the acetanilide in the form of fine, white crystals from alcohol with melting point of $148^{\circ}$.

Calc. for $\mathrm{C}_{8} \mathrm{H}_{7} \mathrm{ONBII}: \mathrm{N}$, 4.1 I. Found: $4.36,4.44$.

The benzoyl derivative is soluble in hot alcohol and melts at $15^{\circ}$.

Calc. for $\mathrm{C}_{13} \mathrm{H}_{9} \mathrm{ONBrI}: \mathrm{N}, 3.48$. Found: $3.6 \mathrm{r}$.

No formamidine was obtained when the aniline was heated with orthoformic ester at $120-30^{\circ}$.

4-Bromo-2-iododiphenylthiourea from phenylmustard oil and the aniline separates from alcohol in fine, white, hair-like crystals, melting at $167^{\circ}$.

Calc. for $\mathrm{C}_{13} \mathrm{H}_{20} \mathrm{~N}_{2} \mathrm{SBrT}: \mathrm{N}, 6.46$. Found: $6.5 \mathrm{x}, 6.68$.

Allyl-4-bromo-2-iodophenylthiourea forms flaky, silver-white crystals from alcohol, melting at $177^{\circ}$.

Calc. for $\mathrm{C}_{10} \mathrm{H}_{10} \mathrm{SBrI}: \mathrm{N}, 7.05$. Found: 7.26.

4-Bromo-2-iodophenylurea results when the aniline and potassium cyanate are heated in glacial acetic acid solution. It is only. slightly soluble in water, but can be crystallized from alcohol. Its melting point is $167^{\circ}$.

Calc. for $\mathrm{C}_{7} \mathrm{H}_{6} \mathrm{ON}_{2} \mathrm{BrI}: \mathrm{N}, 8.2 \mathrm{I}$. Found: 8.04.

Anisal-4-bromo-2-iodoaniline from anisic aldehyde and the aniline on warming; strongly refracting crystals from alcohol, melting at $118^{\circ}$.

Calc. for $\mathrm{C}_{14} \mathrm{H}_{11} \mathrm{ONBrI}: \mathrm{N}, 3.36$. Found: $3.6 \mathrm{I}$.

Cinnamal-4-bromo-2-iodoaniline is soluble in alcohol ether, gasoline and benzene, and melts at $96^{\circ}$.

${ }^{1}$ Am. Chem. J., 22, 275 (1899). 
Calc. for $\mathrm{C}_{15} \mathrm{H}_{15} \mathrm{NBrI}: \mathrm{N}, 3.40$. Found: 3.38 .

The piperonal 4 -bromo-2-iodoaniine melts at $\mathrm{I}_{20}$.

Calc. for $\mathrm{C}_{14} \mathrm{H}_{8} \mathrm{O}_{2} \mathrm{NBrI}: \mathrm{N}, 3.25$. Found: 3.48 .

The o-nitrobenzal-4-bromo-2-iodoaniline has a melting point of $159^{\circ}$.

Calc. for $\mathrm{C}_{13} \mathrm{H}_{8} \mathrm{O}_{2} \mathrm{~N}_{2} \mathrm{BrI}: \mathrm{N}, 6.5 \mathrm{O}$. Found: 6.30 .

Preparation of 4 -Bromo-2,6-diiodoaniline.-When $p$-bromoaniline is treated with 2 molar weights of iodine, as in the previous experiment, a black solid is obtained, which dissolves readily only in warm pyridine. Water precipitates a product which, by treatment with alcohol, can be separated into 4 -bromo-2-iodoaniline and 4-bromo-diiodoaniline. This latter, by repeated crystallization, was obtained as a white solid melting at $148^{\circ}$. The diiodo compound is formed also by the action of iodine (one mol.) on the bromoiodoaniline.

Calc. for $\mathrm{C}_{8} \mathrm{H}_{4} \mathrm{NBrI}_{2}: \mathrm{N}, 3.30$. Found: 3.34 .

In the bromodiiodoaniline, the second iodine atom is probably in the 6-position The compound possesses little basic properties, since in benzene solution it failed to form a hydrochloride.

Preparation of 3-Bromoiodoaniline.-From $m$-bromoaniline and iodine there was obtained an oil volatile with steam, which solidified only after 2 months standing in a desiccator. It then melted at $56^{\circ}$. The compound itself was not analyzed, but the oil first obtained was converted into its hydrochloride, which melts at $192^{\circ}$.

Calc, for $\mathrm{C}_{6} \mathrm{H}_{3} \mathrm{NCII} . \mathrm{HCl}$ : 10.90 . Found: 10.77 , 10.64.

The acetanilide from the amine and acetic anhydride melts at $199^{\circ}$.

Calc. for $\mathrm{C}_{8} \mathrm{H}_{7} \mathrm{ONBrI}: \mathrm{N}$, 4.r. Found: 4.30, 4.02.

In the case of the $m$-ch'oroaniline, as is noted later, the iodine atom entered the 4-position. It is very probable that the same reaction occurred here, but the exact proof must be deferred until later.

The Introduction of Iodine into the Chloroanilines.

Preparation of 4-Chloroiodoaniline.-These react under the usual conditions and on distilling the product with steam, an oil comes over which slowly solidifies. The compound, which melts at $46^{\circ}$, can be purified by dissolving in gasoline and cooling with ice, or it can be crystallized from hot water, in which it is slightly soluble.

Calc. for $\mathrm{C}_{6} \mathrm{H}_{3} \mathrm{ClINH}_{2}: \mathrm{N}, 5.52 ; \mathrm{Cl}, 14.00 ; \mathrm{I}, 50.07$. Found: $\mathrm{N}, 5.63: \mathrm{Cl}, \mathrm{I}_{4}, \mathrm{OI}$; I, 50.13 .

The analysis and reactions indicate that it is a 4 -chloroiodoaniline and from analogy to the 4 -bromo-2-iodoaniline, the iodine has doubtless entered the 2 position, although that point will be proved definitely later.

Derivatives of 4 -Chloroiodoaniline.-The hydrochloride melts with decomposition at $202^{\circ}$. 
Calc. for $\mathrm{C}_{8} \mathrm{H}_{5} \mathrm{NClI} . \mathrm{HCl}: \mathrm{HCl}, \mathrm{12} .58$. Found: $\mathrm{x} 2.5 \mathrm{r}$, 22.60 .

4-Chloroiodoacetanilide, from acetic anhydride and the aniline gives white crystals from alcohol, melting at $150^{\circ}$.

Calc. for $\mathrm{C}_{8} \mathrm{H}_{7} \mathrm{ONClI}: \mathrm{N}, 4.74$. Found: $4.75,4.86$.

The benzanilide melts at $145^{\circ}$ and can be purified by crystallization from gasoline or alcohol.

Calc. for $\mathrm{C}_{13} \mathrm{H}_{9} \mathrm{ONCII}$ : $\mathrm{Cl}, 9.93 ; \mathrm{I}, 35.52$. Found: $\mathrm{Cl}, 9.98,9.94 ; \mathrm{I}, 35.70,35.22$.

In one experiment, using only molar quantities of $p$-chloroaniline and iodine, there was obtained as the main product $p$-chlorodiiodoaniline. The black solid formed was purified by recrystallization from alcohol, from which it separated in white needles, melting at $129^{\circ}$.

Calc. for $\mathrm{C}_{6} \mathrm{H}_{4} \mathrm{NClI}_{2}: \mathrm{N}, 3.69$. Found: $3.63,3.80$.

The introduction of 3 halogen atoms has decreased the reactivity of the compound. It failed to form a hydrochloride in benzene solution, nor did it give an acetyl derivative on boiling with açetic anhydride and sodium acetate.

When heated with benzoyl chloride, the benzanilide was obtained. This, after purification from alcohol, melted at $205^{\circ}$.

Calc. for $\mathrm{C}_{18} \mathrm{H}_{8} \mathrm{ONClI}_{2}: \mathrm{N}, 2.97$. Found: $3.09,3.27$.

Preparation of 2-Chloro-4-iodoaniline.-A molar mixture of 0-chloroaniline and iodine, together with calcium carbonate, ether and water was heated and the reaction product distilled with steam. A brown oil came over which slowly solidified. It was purified by solution in alcohol and boiling with animal charcoal. Water precipitated from the alcohol solution white crystals which melted at $73^{\circ}$.

Calc. for $\mathrm{C}_{8} \mathrm{H}_{3} \mathrm{ClINH}_{2}: \mathrm{N}, 5.52$. Found: $5.53,5.64$.

The compound is identical with a 4 -iodochloroaniline (m. p. $73^{\circ}$ ) obtained by Werner and Caldwell. ${ }^{1}$ Starting with $p$-iodoacetanilide, they made the iodidechloride $\mathrm{CH}_{3} \mathrm{CONHC}_{6} \mathrm{H}_{4} \mathrm{ICl}_{2}$. This, on heating, gave the 4-iodochloroacetanilide (m. p. $144^{\circ}$ ), which on hydrolysis yielded the 4 -iodochloroaniline $\left(\mathrm{m} . \mathrm{p} \cdot 73^{\circ}\right)$. They obtained a picrate (m. p. $\left.\mathrm{r} 32^{\circ}\right)$ and with phenyl isothiocyanate, the thiourea (m. p. $15^{\circ}$ ). The aniline (m. p. $73^{\circ}$ ) which we obtained gave also an acetyl, picrate, and a mustard oil derivative with the above melting points, the formula of each compound being confirmed by analysis. Its constitution as a 2 -chloro-4-iodoaniline is therefore established, since in one case the starting point was 2-chloroand in the other 4-iodoaniline.

Derivatives of 2-Chloro-4-iodoaniline.-The hydrochloride melts with decomposition at $190^{\circ}$.

Calc. for $\mathrm{C}_{6} \mathrm{H}_{5} \mathrm{NClI} . \mathrm{HCl}: \mathrm{HCl}$, 2.58 . Found: 12.50 , 12.44 .

I J. Chem. Soc., 9I, 246 (1907). 
The betnzanilide is slightly soluble in cold alcohol, and melts at $165^{\circ}$.

Calc. for $\mathrm{C}_{13} \mathrm{H}_{9} \mathrm{ONClI}: \mathrm{N}, 3.92$. Found: 3.99 , 4.I I.

The phenyl urea $\mathrm{C}_{6} \mathrm{H}_{3} \mathrm{CINHCONH}$ can be crystallized from alcohol, and has a melting point of $175^{\circ}$.

Calc, for $\mathrm{C}_{7} \mathrm{H}_{6} \mathrm{ON}_{2} \mathrm{ClI}$ : Cl, II.97; I, 42.83. Found: $\mathrm{Cl}$, II.88, I2.05; I, 42.53, 43.15.

Preparation and Proof of Constitution of 3-Chloro-4-iodoaniline. $-m$ Chloroaniline was allowed to react with iodine in the usual manner. The steam distillate on standing deposited crystals which were filtered off, dissolved in alcohol and decolorized with animal charcoal. The alcoholic solution on diluting with ice water deposited the pure 3 -chloro-4iodoaniline, which melted at $65^{\circ}$. The yield was poor.

Calc. for $\mathrm{C}_{6} \mathrm{H}_{5} \mathrm{NClI}: \mathrm{N}, 5.52$. Found: $5.57,5.49$.

It has been shown that in the iodination of the 2 -chloroaniline, the iodine entered the 4-position. If the same 4-position is occupied when 3 -chloroaniline is treated with iodine, then on replacing the amino group by iodine, both chloroiodoanilines would give the same I,4-diiodo-2chlorobenzene. Experiment proved this to be the case.

2-Chloro-4-iodoaniline was diazotized and treated at $0^{\circ}$ with a solution of potassium iodide. On standing a dark red oil separated. The contents of the flask were warmed and distilled with steam. The dark oil which came over solidified on standing. 'This, after boiling in alcohol with animal charcoal, gave white crystals melting at $51^{\circ}$. The analysis corresponded to a diiodochlorobenzene.

Calc. for $\mathrm{C}_{6} \mathrm{H}_{8} \mathrm{ClI}_{2}$ : Cl, 9.74; I, 69.68. Found: $\mathrm{Cl}, 9.68,8.74 ; \mathrm{I}, 69.55,70.18$.

When the supposed 3-chloro-4-iodoaniline was diazotized in the same manner, it gave a diodochlorobenzene, melting at $5 \mathrm{I}^{\circ}$ and identical in every way with the known I,4-diiodo-2-chlorobenzene.

Derivatives of 3-Chloro-4-iodoaniline.-The hydrochloride separates in the form of white crystals, melting with decomposition at $180^{\circ}$.

Calc. for $\mathrm{C}_{6} \mathrm{H}_{5} \mathrm{NClT} . \mathrm{HCl}: \mathrm{HCl}, 12.58$. Found: $12.59,12.47$.

Acetic anbydride readily gives the 3-chloro-4-iodoacetanilide, which crystallizes from alcohol in white needles, with a melting point of $170^{\circ}$.

Calc, for $\mathrm{CH}_{3} \mathrm{CONHC} \mathrm{H}_{3} \mathrm{CII}: \mathrm{N}, 4.72$. Found: $4.73,4.82$.

The benzanilide melts at $144^{\circ}$.

Calc. for $\mathrm{C}_{13} \mathrm{H}_{8} \mathrm{ONCII}: \mathrm{N}, 3.92$. Found: $3.88,3.78$.

Preparation of 2,4-Dichloroiodoaniline.-While iodine and aniline react readily, giving the $2,4,6$-triiodoaniline, the introduction of iodine into the 2,4-dichloroaniline occurs only with difficulty. Ten hours' heating of the 2 substances gave only a small yield of white crystalline product, slowly volatile with steam, which melted at $85^{\circ}$. Analysis showed this to be the 2,4-dichloro-6?-iodoaniline. 


\section{I, 43.98 .}

Calc. for $\mathrm{C}_{6} \mathrm{H}_{2} \mathrm{Cl}_{2} \mathrm{INH}_{2}: \mathrm{N}, 4.83 ; \mathrm{Cl}, 24.65 ; \mathrm{I}, 4.09$. Found: $\mathrm{N}, 4.76 ; \mathrm{Cl}, 24.65$;

The compound, when dissolved in benzene and treated with hydrogen chloride, gave an impure hydrochloride, melting at $180^{\circ}$. There was found on analysis only $8.25 \% \mathrm{HCl}$ instead of the required $\mathrm{II} .25 \%$. Even this amount decreased rapidly on standing.

The Action of Iodine on Non-halogenated Aromatic Amines.--The investigations on the direct introduction of iodine in the foregoing fashion have dealt with aniline, the halogen anilines or the toluidines. In the majority of cases it has been found that the reaction proceeds fairly smoothly, good yields being obtained. When, however, the hydrogen of the ring is replaced with 2 or 3 methyl groups or with a methoxy, ethoxy or acetamino grouping, the yield of the simple iodine derivative may be very much lessened or there may be formed only resinous, iodine-containing condensation products. Under like conditions the mono- and dimethylanilines tend to give the same complex resins.

Pseudocumidine reacts with iodine, giving a large amount of resinous material and a small yield of 2-iodo-3,4,6-trimethylaniline, melting at $93^{\circ}$.

Calc. for $\mathrm{C}_{9} \mathrm{H}_{12} \mathrm{NI}: \mathrm{N}, 5.36$. Found: $5.44,5.46$.

This had been previously prepared by Kirschbaum by the action of iodine monochloride on the cumidine. The hydrochloride melts at I92- $3^{\circ}$. In like manner he obtained 6-iodo-3,4-dimethylaniline ${ }^{1}$ (m. p. $\left.65^{\circ}\right)$, also formed from iodine and as m-xylidine.

Calc. for $\mathrm{C}_{8} \mathrm{H}_{10} \mathrm{NI}: \mathrm{N}, 5.67$. Found: $5.63,5.52$.

$o$-Anisidine and iodine react, yielding a product slowly volatile with steam, which, after crystallization from dilute alcohol, melted at $49^{\circ}$. The analytical figures and reactions indicate that it is a 2 -methoxy-4?iodoaniline.

Calc. for $\mathrm{C}_{7} \mathrm{H}_{8} \mathrm{ONI}: \mathrm{N}, 5.62 ; \mathrm{I}, 5$ I.00. Found: N, $5.29 ; \mathrm{I}, 50.76$.

The hydrochloride melts at $180^{\circ}$.

Calc. for $\mathrm{C}_{7} \mathrm{H}_{8} \mathrm{ONI}: \mathrm{HCl}, 12.78$. Found: 12.88 .

The iodo-2-methoxyacetanilide, after recrystallization from alcohol, had a melting point of $176^{\circ}$.

Calc. for $\mathrm{C}_{9} \mathrm{H}_{10} \mathrm{O}_{2} \mathrm{NI}: \mathrm{N}, 4.8 \mathrm{I} ; \mathrm{I}, 43.69$. Found: $\mathrm{N}, 4.88 ; \mathrm{I}, 43.79$.

When $p$-anisidine was heated with iodine, the only product obtained was a black, waxy, resinous substance, somewhat soluble in alcohol, acetone and benzene, and readily soluble in pyridine. It was found impossible to purify it satisfactorily. Analysis showed that it contained iodine, and it would seem probable that it was a condensation product of two or more moles of an iodo- $p$-anisidine.

1 Ber., 28, 2799, 2809 (1895). 
p-Acetphenylenediamine behaved in a similar manner. The reaction product consisted of a black iodine-containing solid melting between $240-50^{\circ}$ and only slightly soluble in the usual organic solvents.

\section{The Determination of Halogens in Organic Compounds.}

The halogen determinations in the preceding paper were made by a liquid ammonia process which has been found to give very good results in this laboratory and to be much simpler than the usual methods. Some years ago Dr. H. P. Cady noted the fact that when sodium was added to an organic halogen derivative in liquid ammonia, the halogen was removed quantitatively. Enough experimental work was carried on to indicate that the method was a practical one. Somewhat later it was developed more fully in the organic laboratory and has been used successfully for several years. After this had been done it was found that the same procediure had been devised by $\mathrm{E}$. Chablay. ${ }^{1}$

The following method, though essentially the same, is somewhat more convenient than that of Chablay. A small quantity of the substance (usually less than $0.1 \mathrm{~g}$. in the case of iodine compounds) is placed in a Dewar bulb and about $30 \mathrm{cc}$. of liquid ammonia added. When the material is in solution, although this is not essential if it is finely divided, a small piece of sodium is added. An excess is used, which is indicated by the blue color of the solution. The material is stirred and allowed to stand until all the ammonia has evaporated. The excess of sodium can be taken up in the ammonia solution with solid ammonium nitrate, or a little alcohol can be added to the residue. This is not necessary, however, unless a large excess of sodium has been used. The residue, after the evaporation of the ammonia, is dissolved in water, acidified with nitric acid, an excess of 0 . I $N$ or $0.025 N$ silver nitrate added, filtered and the filtrate titrated with standard ammonium thiocyanate solution, using ferric alum as an indicator.

The process can be recommended as the shortest and most simple method for halogen determinations in organic compounds. It may be of interest to note that calcium, which is also soluble in liquid ammonia, has been used with success in the determination of chlorine in 4-chloroaniline.

\section{Summary.}

Experimental work has been carried out along the following lines:

(I) The action of iodine on chloro- and bromaanilines.

(2) The action of iodine on cumidine, xylidine, anisidine and acetphenylenediamine.

(3) A method for the determination of halogens in organic compounds.

A Ann.chim., [9] I, 516 (1914). 